\title{
Worksite Physical Activity Interventions and Obesity: A Review of European Studies (the HOPE Project)
}

\author{
Anne Vuillemin ${ }^{a, b}$, Cyrus Rostamia ${ }^{a}$, Lea Maes ${ }^{c}$, Eveline Van Cauwenberghe ${ }^{d}$, \\ Frank J. Van Lenthe ${ }^{\mathrm{e}}$, Johannes Brug ${ }^{f}$, Ilse De Bourdeaudhuij ${ }^{\mathrm{d}}$, Jean-Michel Opperta, \\ ${ }^{a}$ Nutritional Epidemiology Unit, UMR U557 Inserm, U1125 Inra, Cnam, Université Paris 13, CRNH IdF, Bobigny, \\ ${ }^{\mathrm{b}}$ Nancy-University, University Paul Verlaine Metz, University Paris Descartes, EA 4360 Apemac, Nancy, France \\ ${ }^{\circ}$ Department of Public Health, \\ ${ }^{\mathrm{d}}$ Department of Movement and Sport Sciences, Ghent University, Belgium \\ ${ }^{e}$ Department of Public Health, Erasmus University Medical Centre Rotterdam \\ ${ }^{f}$ EMGO Institute for Health and Care Research, VU University Medical Centre, Amsterdam, the Netherlands \\ ${ }^{g}$ Department of Nutrition, University Pierre et Marie Curie, Pitie-Salpêtriere Hospital (AP-HP), Centre for Research on Human \\ Nutrition Ile-de-France (CRNH IdF), Paris, France
}

\author{
Keywords \\ Physical activity · Obesity · Intervention studies . \\ Worksite - External validity.
}

\section{Summary}

Objective: Our aim was to review the effectiveness of physical activity promotion interventions in the worksite setting in Europe in order to identify those studies that had measured obesity-related outcomes and to evaluate how external validity of the findings had been assessed. Methods: We conducted a review of studies conducted in Europe, published up to December 2009. We assessed levels of evidence regarding effectiveness and analysed external validity using the RE-AIM framework. Results: Studies included ( $n=33$ ) were divided in 6 intervention categories. Moderate evidence of effectiveness was found for physical fitness outcomes with exercise training interventions and for physical activity outcomes with active commuting interventions. There was no or inconclusive evidence for obesity-related outcomes for all intervention categories. For external validity, elements receiving the least attention $(<20 \%)$ were representativeness of participants, setting-level inclusion/exclusion criteria and representativeness, characteristics regarding intervention staff, implementation of intervention, costs, long-term effects and programme sustainability. Conclusions: Active commuting and exercise training appear as promising approaches to promote physical activity or fitness in the workplace. The effect of interventions on obesity-related outcomes remains to be further investigated. There is a need to better report elements of generalizability and dissemination for translation into practice of worksite physical activity interventions.

\section{Introduction}

The worksite is considered as an important setting to implement programmes and strategies both to promote physical activity and to prevent body weight gain and obesity $[1,2]$. The worksite represents a relatively controlled environment, and a substantial proportion of the adult population can be reached through worksite interventions. For employers, the possibility of increasing productivity [3] while reducing health care costs through the reduction of sick leaves and accidents may represent a strong incentive for the implementation of worksite programmes designed to increase physical activity [4].

Among previous reviews that have assessed the published evidence regarding the effectiveness of physical activity promotion interventions in the worksite setting [1,4-10], only three [8-10] have focused on obesity-related outcomes with inconclusive evidence of effectiveness. Although it may be of major interest for practical implementation, studies were not categorized by type of intervention in these reviews. In addition, to translate research findings into practice and policy,

\section{KARGER \\ Fax +497614520714 \\ Information@Karger.de}

www.karger.com
(C) 2011 S. Karger GmbH, Freiburg

$1662-4025 / 11 / 0046-0479 \$ 38.00 / 0$

Accessible online at:

www.karger.com/ofa
Prof. Dr. Jean-Michel Oppert

Department of Nutrition, Pitié-Salpêtrière Hospital (AP-HP)

83, Boulevard de l'Hôpital, 75013 Paris, France

Tel. +331 42 1779-48, Fax -63

jean-michel.oppert@psl.aphp.fr 
there is increasing interest in the assessment of external validity of available research data but these issues relative to external validity have received less attention [11]. The extent to which research has reported on elements of external validity in the field of worksite physical activity interventions has not been examined in detail. The RE-AIM framework $[12,13]$ is a tool that has been designed for such purpose. Using this framework, the public health impact of an intervention may be described as a function of five factors: Reach (the target population), Efficacy (impact on important outcomes), Adoption (by target settings or institutions), Implementation (consistency of delivery of intervention) and Maintenance (of intervention effects in individuals and settings over time).

The HOPE (acronym for Health-promotion through Obesity Prevention across Europe, see www.hopeproject.eu) European Commission-funded project (DG Research) aims at supporting and advancing the development and implementation of systematic, evidence-based European, national and regional policies effective for the prevention of obesity and its negative consequences on health and health inequalities, by providing information and inventories of obesogenic behaviours, such as physical inactivity, important environmental determinants of these behaviours and effective intervention approaches across Member States. Because the traditions of health promotion and disease prevention in the workplace appear quite different between continents [4], it appears of importance to identify the types of interventions that would be generalised in European settings.

The aim of our work in this part of the HOPE project was therefore to update the issue of effectiveness of physical activity promotion interventions in the worksite setting with a specific focus on interventions conducted in Europe. We included worksite interventions that had examined physical activity or physical fitness outcomes, and we identified among these studies those that had measured obesity-related outcomes. Using the RE-AIM framework, an additional aim was to evaluate if and how aspects of external validity of the findings had been assessed.

\section{Material and Methods}

\section{Literature Search, Selection of Studies and Data Extraction}

Studies published from January 1990 up to December 2009 were located by searches using PubMed, EMBASE, CINAHL, PsycINFO, SportDiscus, Web of Science and Cochrane. Thesaurus terms and free terms were used for each database. The initial search was centred on the following elements: worksite, physical activity, exercise, intervention, primary prevention, using combinations of terms depending on the database searched. This was completed by manual search of relevant references found in individual papers or existing reviews.

To be eligible for inclusion in the review, studies had to 1) be published in English between 1990 and December 2009, 2) study the effectiveness of interventions aimed at increasing physical activity of employees in a workplace, 3 ) be aimed at working adults in general (over
18 years), 4) be specifically carried out in a worksite setting (including commuting to work as part of active transport), 5) be performed in Europe (not restricted to EU member states but encompassing the whole of Europe Region as defined by WHO (www.euro.who.int), 6) be a primary prevention study. To have a broad approach of the topic, we did not restrict our search to only randomised controlled trials (RCTs). The outcome measure had to be a difference in change in physical activity such as habitual physical activity level, and/or in physical fitness such as cardiorespiratory fitness, strength, and/or in obesity-related outcomes such as BMI, body weight, percentage body fat, waist circumference or waistto-hip ratio. Data from studies that met the inclusion criteria were extracted by one reviewer (CR) into structured templates and checked by a second reviewer (JMO).

\section{Assessment of Evidence of Effectiveness}

We assessed methodological quality using a scale that was derived from previous published systematic literature reviews on effectiveness of physical activity interventions at the workplace [7] and in children and adolescents [14]. The 11 criteria we included for quality assessment were as follows: 1) randomisation (randomisation was performed and, if yes, the randomisation procedure was described), 2) comparability between intervention and control groups at baseline, 3) inclusion/exclusion criteria were indicated, 4) follow-up (a minimum of 6 months was set), 5) drop outs (number indicated, reasons for described), 6) validated measures used for physical activity outcomes, 7) compliance, 8) timing of measurements (similar between intervention and control groups), 9) blinding (whether intervention providers and participants were aware of the research question), 10) intention-to-treat analyses, 11) confounders taken into account in the analyses. Items were scores 'positive', 'negative', 'not applicable' or 'unclear'. Scores were then summed, and high quality was defined by a total of 6 for RCTs and a total or 5 or more for other study designs. All included studies were rated independently by two reviewers (CR, JMO). When opinions differed, consensus on ratings was reached through discussion.

For effectiveness, we followed the grading of evidence proposed by Van Sluijs et al. [14] based on sample size (under 250 subjects is considered small, over 250 is considered large), design (randomised or nonrandomised controlled trial) and methodological quality as detailed above. Available results were judged consistent when two thirds of results of relevant studies were found significant and in the same direction [14]. On that basis, five levels of evidence are possible: strong, moderate, limited, inconclusive and no evidence. Given the heterogeneity of studies examined in terms of design, type of intervention, participants, measures and outcomes, a meta-analysis of pooled effects was not considered.

\section{RE-AIM Framework}

RE-AIM is a five-step framework designed to translate research into action [12]. RE-AIM criteria have been presented as key quality rating criteria for reporting on external validity [13], and the RE-AIM Framework has been used recently for this purpose in obesity prevention research (in children) [15]. We used the following criteria to assess the reviewed studies: 1 ) reach (e.g. participation rate and representativeness of individuals), 2) efficacy on selected outcomes (e.g., whether outcomes were compared to a standard goal, whether adverse effects were reported), 3) adoption (e.g., participation rate and representativeness of community or worksite settings), 4) implementation (e.g., levels of interventionist expertise and training, consistency of delivery, adaptation of an approach to local circumstances), 5) maintenance and sustainability (e.g., which components are institutionalized or modified over time).

All articles were coded by two reviewers (JMO, AV) who independently evaluated each study for whether it reported information on each external validity criteria. Discrepancies were resolved by discussion and clarification. Results are reported as the percentage of papers that reported on the respective external validity criteria. 


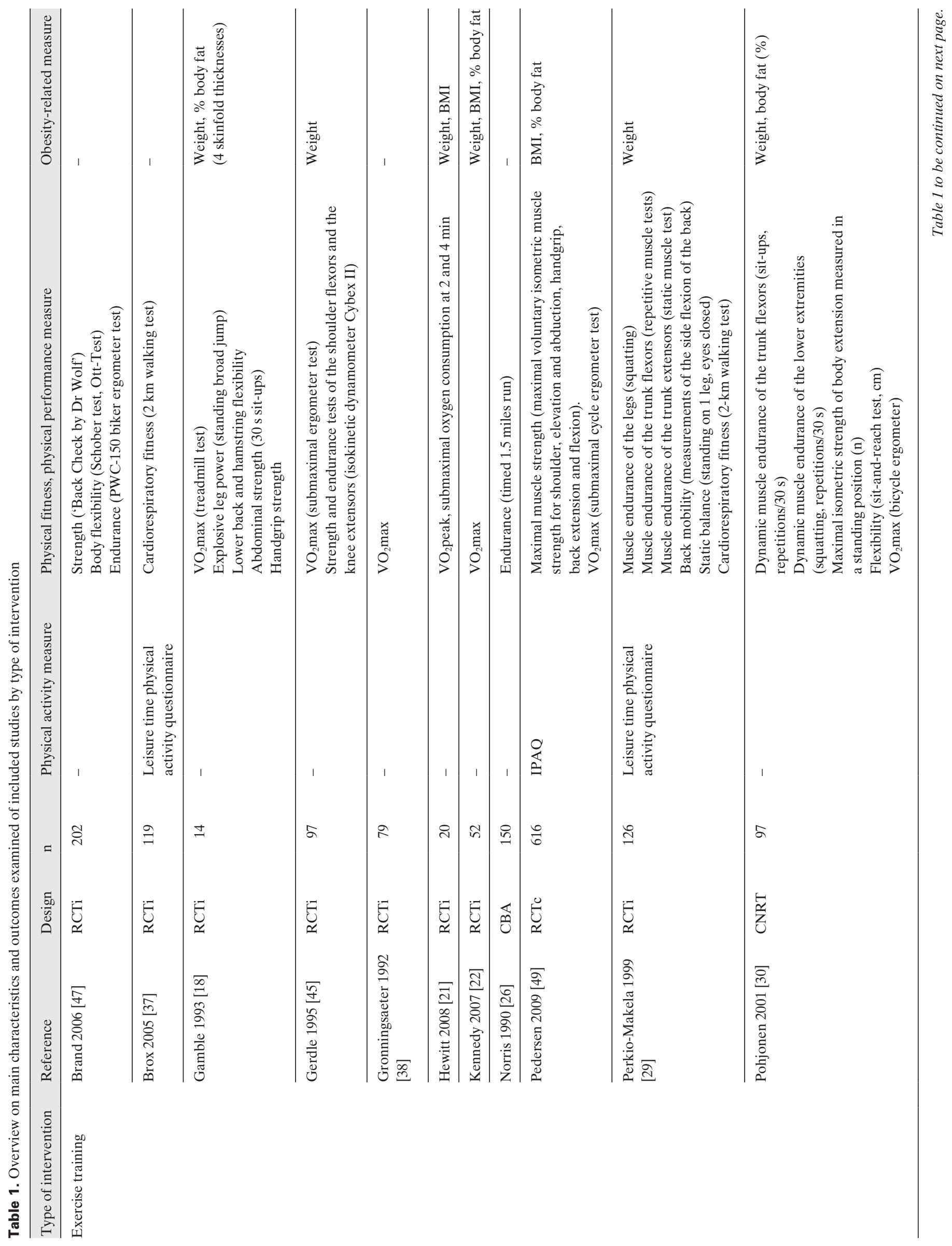




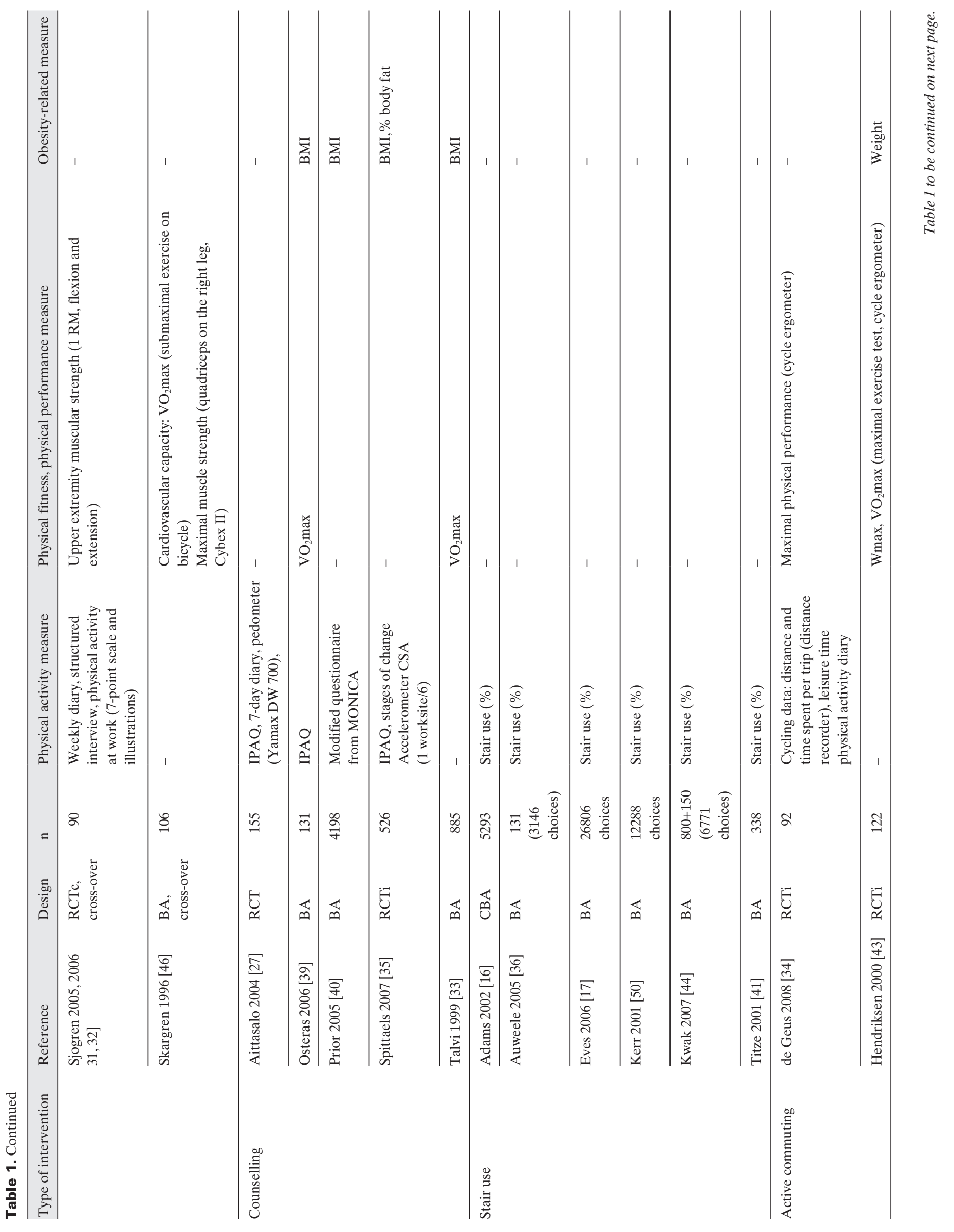




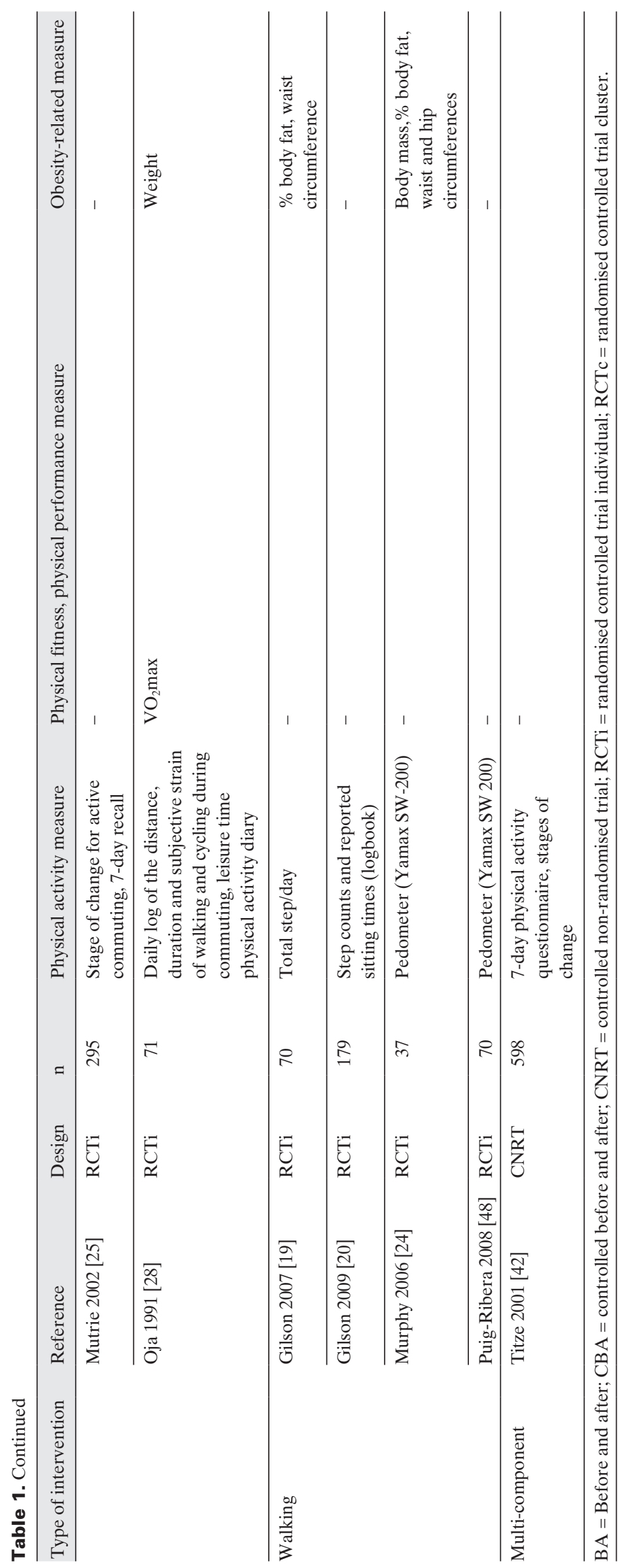

\section{Results}

\section{Types of Interventions and Designs}

33 European studies met the inclusion criteria and were fully analysed. Studies originated from 10 European countries: UK [16-26] $(\mathrm{n}=11$ studies, 33\%), Finland [27-33] $(\mathrm{n}=6,18 \%)$, Belgium [34-36], Norway [37-39] and Switzerland [40-42] ( $\mathrm{n}=3$ each, 9\%), the Netherlands [43, 44] and Sweden [45, 46] ( $\mathrm{n}=2$ each, 6\%), Germany [47], Spain [48] and Denmark [49] ( $\mathrm{n}=1$ each, 3\%). To better describe the types of interventions, six categories were used: 1) counselling $(n=5,15 \%)[27,33,35,39,40] ; 2)$ exercise training $(\mathrm{n}=13,39 \%)$ with 10 aerobic fitness and muscular training [18, 21, 26, 29, 30, 32, 37, 45-47, 49], one aerobic fitness training with stress management strategies [38] and one stair climbing training [22]; 3) active commuting ( $\mathrm{n}=$ $4,12 \%)$ with 2 cycling [34, 43] and 2 cycling and walking $[25,28]$; 4) walking interventions $(\mathrm{n}=4,12 \%)[19,20,24$, $48]$; 5) stair use $(\mathrm{n}=6,18 \%)$ with signs and prompts-ofchoice [16, 17, 36, 41, 44, 50]; and 6) multi-component intervention (associating a physical activity educational programme, commuting, walking and counselling interventions) $(\mathrm{n}=1,3 \%)$ [42]. Table 1 presents the design of the study, the number of participants involved and the outcomes examined, by type of intervention. 20 out of 33 studies (61\%) were RCTs [18-22, 24-29, 32, 34, 35, 37, 38, 43, 45, 47-49] (2 used cluster-randomised designs [32, 49]), $2(6 \%)$ were controlled non-randomised trials [30, 42], 2 $(6 \%)$ were controlled before and after studies [16, 26] and $9(27 \%)$ studies had a pre-post design $[17,33,36,39-41,44$, 46, 51]. 15 studies $(45 \%)$ considered obesity-related outcomes [18, 19, 21, 22, 24, 28-30, 33, 35, 39, 40, 43, 45, 49], with only 1 study where this was a primary outcome [22]. 22 studies $(67 \%)$ considered increased physical activity as outcome [16, 17, 19, 20, 24, 25, 27-29, 31, 32, 34-37, 39-42, $44,48,49,51]$, and 18 studies $(54 \%)$ considered physical fitness improvement as outcome [18, 21, 22, 26, 28-34, 37$39,43,45-47,49]$.

\section{Evidence of Effectiveness}

Table 2 shows the main results regarding evidence of effectiveness on physical activity, physical fitness and obesity-related outcomes by type of intervention. For these outcomes, the evidence was graded as inconclusive for counselling, walking, stair use and multi-component interventions whatever the outcome considered. The evidence was graded as moderate for exercise training (physical fitness outcomes) and limited (physical fitness outcomes) to moderate (physical activity outcomes) for active commuting studies. There was either no evidence (active commuting) or inconclusive evidence (counselling, exercise training, walking) of effec- 
tiveness for obesity-related outcomes. In total, 17 studies (52\%) were considered of high methodological quality (16 of 17 were randomised controlled trials), and 9 among them were exercise training studies ( 8 of 13 were RCTs).

\section{Reporting of External Validity Dimensions}

Table 3 summarises the percentage of studies reporting various external validity dimensions using the coding framework. In general, all studies lacked full reporting on potential generalisability and dissemination elements. Elements receiving the least attention $(<20 \%)$ were representativeness of participants, setting-level inclusion/exclusion criteria and representativeness, characteristics regarding intervention staff (participation rate, implementation and effect moderator), implementation of intervention content, costs, long-term effects and programme sustainability.

\section{Reach}

At the level of individual participants, almost all types of intervention studies reported on the target audience description, except for studies on stair use (67\%). The individual inclusion/exclusion criteria and the participation rate were frequently reported ( $\geq 50 \%)$, but not for multi-component (individual criteria) and stair use (participation rate) interventions. The representativeness of participants was described in exercise training (31\%) and counselling (20\%) studies only.

\section{Efficacy}

All studies on walking $(\mathrm{n}=4)$ and multi-component interventions $(\mathrm{n}=1), 15 \%(\mathrm{n}=2 / 13)$ of exercise training and $40 \%$ ( $n=2 / 5)$ of counselling interventions compared their physical activity and physical fitness outcomes to current recommendations for physical activity or to defined public health goals. An effect moderator by participant characteristics was reported in the majority of studies $(n=17 / 33$ total number of studies, $n=3 / 13$ for exercise training, $n=4 / 5$ for counselling, $n=5 / 6$ for stair use, $n=4 / 4$ for active commuting and $n=1$ for multi-component interventions). In contrast, an effect moderator by staff/setting was reported in 3 studies only (1 active commuting and 2 stair use interventions).

\section{Adoption}

At the setting level, the intended target setting description was mostly reported (60-100\% depending on type of intervention), but not the setting inclusion/exclusion criteria, participation rate or representativeness. No information was provided on delivery staff.

\section{Implementation}

Except for the only multi-component intervention included in the review [42], studies on counseling and stair use were more likely to describe a consistent implementation of their pro-

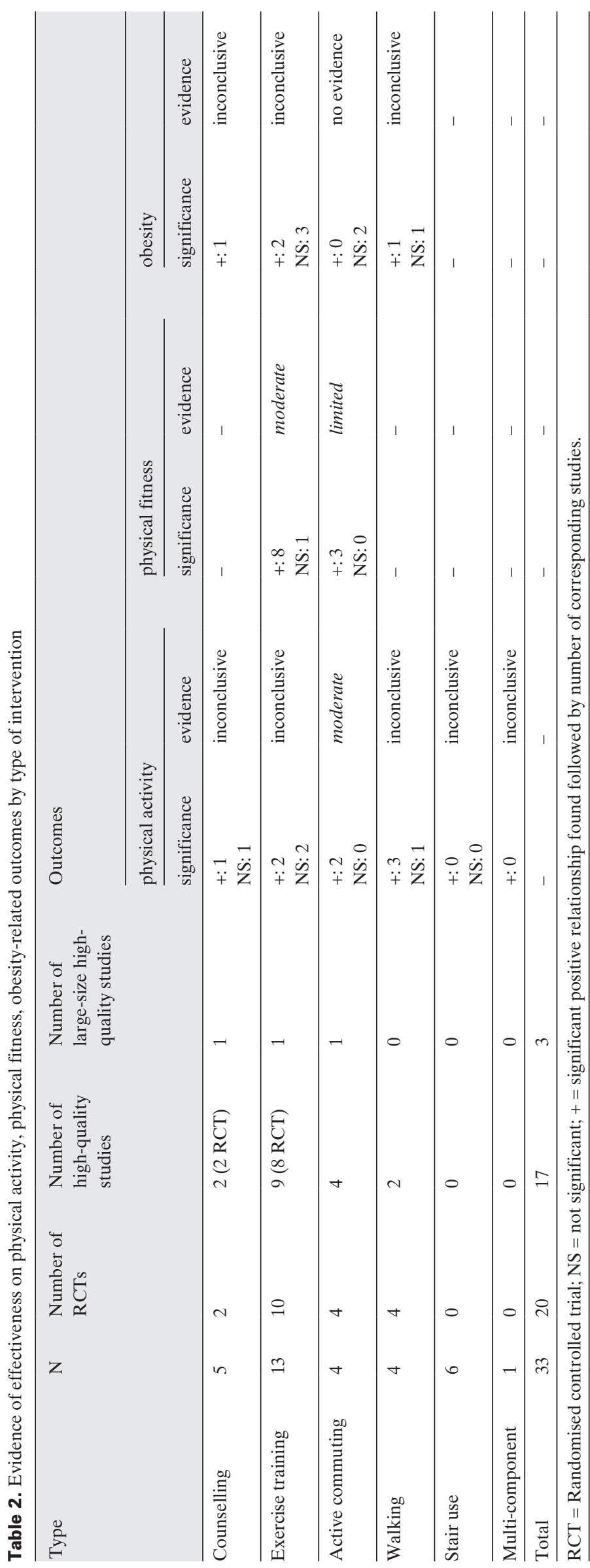

Vuillemin/Rostami/Maes/Van Cauwenberghe/ Van Lenthe/Brug/De Bourdeaudhuij/Oppert 
Table 3. Percentage of studies reporting external validity dimensions (using RE-AIM framework) ${ }^{\mathrm{a}}$

n $\quad \%$ reporting

\begin{tabular}{lrr}
\hline Reach & & \\
Individual participants & 31 & 94 \\
$\quad$ Target audience description & 22 & 67 \\
$\quad$ Individual inclusion/exclusion criteria & 19 & 58 \\
Participation rate & 5 & 15 \\
$\quad$ Representativeness of participants & \\
\hline
\end{tabular}

\begin{tabular}{lrr}
\hline Efficacy (on selected outcomes) & & \\
Outcomes compared to standard goal & 9 & 27 \\
Adverse consequences & 10 & 30 \\
Effect moderator by participant characteristic(s) & 17 & 52 \\
Effect moderator by staff/setting & 3 & 9 \\
\hline Adoption & & \\
Setting level & 24 & 73 \\
$\quad$ Target setting description & 6 & 18 \\
$\quad$ Setting inclusion/exclusion criteria & 7 & 21 \\
$\quad$ Participation rate & 1 & 3 \\
$\quad$ Representativeness of setting & & \\
Delivery staff & 0 & 0 \\
$\quad$ Participation rate &
\end{tabular}

\begin{tabular}{lrr}
\hline Implementation & & \\
Consistent implementation of program & 10 & 30 \\
Staff expertise or training & 17 & 52 \\
Implementation differed by staff & 0 & 0 \\
Program adaptation & 7 & 21 \\
Number of sessions or time needed to deliver & 33 & 100 \\
$\quad$ intervention & & \\
Costs & 0 & 0 \\
\hline
\end{tabular}

Maintenance and sustainability

Long-term effects (at least 12 months)

Program sustainability

Attrition rate

\begin{tabular}{rr}
4 & 12 \\
1 & 3 \\
25 & 76 \\
12 & 36 \\
7 & 21 \\
\hline
\end{tabular}

Drop-out representativeness

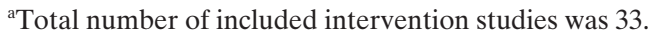

gramme ( $n=3 / 5,60 \%$ and $n=4 / 6,67 \%$ respectively) compared to the others (active commuting, $n=1 / 4,25 \%$; exercise training, $\mathrm{n}=1 / 13,8 \%$; walking, $\mathrm{n}=0 / 4,0 \%$ ).

For studies on exercise training and counseling, staff expertise was specified $(n=10 / 13,78 \%$ and $n=3 / 5,60 \%$ respectively), but no data on quality of implementation by different types of staff was presented, whatever the type of intervention. Programme adaptation was reported in 3 out of 13 $(23 \%)$ exercise training studies, in 2 out of $6(33 \%)$ stair use studies, in 1 out of $4(25 \%)$ walking studies and in the multicomponent study. All studies, whatever type of intervention, reported on the number of sessions or time needed to deliver intervention. No information was provided on costs in any study.

\section{Maintenance and Sustainability}

Only 4 studies, 2 exercise training and 2 counselling intervention studies, performed a follow-up evaluation 12 months after the end of the intervention. Only 1 study, which was an active commuting intervention, reported information related to the sustainability of the programme. Regarding attrition, 7 studies did not report clearly on this issue. However, 6 of these studies were stair use interventions where this information was not relevant. Differential attrition by condition tested and drop-out representativeness were only reported in active commuting ( $\mathrm{n}=4 / 4,100 \%$ and $\mathrm{n}=2 / 4,50 \%$, respectively) and multi-component (100\% both) intervention studies.

\section{Discussion}

Our review identified 33 studies on the effectiveness of physical activity interventions at the workplace conducted in Europe. Settings, intervention characteristics and outcomes were very heterogeneous, and the analysis of evidence of effectiveness led to overall mixed results. Our findings suggest that, to date, whatever the type of worksite intervention considered, there is no evidence or only inconclusive evidence for an effect on obesity-related outcomes. We found only limited to moderate evidence for active commuting interventions on physical fitness and physical activity outcomes, whereas moderate evidence was observed for exercise training on physical fitness outcomes. Importantly, a majority of studies did not report the generalisability elements of key importance for future translation and dissemination of interventions.

Among the particularity of our review we can emphasise the large inclusion criteria, the categorisation by type of interventions and the focus on obesity-related outcomes. The grading of evidence for effectiveness that we used was mainly based on the number of studies available, sample size, methodological quality and the significance of results. Using this grading system, one important finding was the moderate evidence of effectiveness of exercise training interventions on physical fitness outcomes. This category comprised the greatest number of studies included in the review, included the greatest number of RCTs and had the greatest number of significant results, therefore strongly influencing the rating of the evidence. In addition, it should not come as a surprise that exercise training does improve physical fitness, whatever setting $[52,53]$. In contrast, for this same type of intervention, there was only inconclusive evidence of effectiveness on obesity-related outcomes. It should however be noted that only half of the training studies had measured weight outcomes, and only half of the latter studies considered body fat as outcome. Indeed, training may be associated with increased fat-free mass and decreased fat mass, resulting in no change in body weight [54]. These findings illustrate first the lack of 
data for obesity-related outcomes in included studies and also the need to include body composition data to better assess intervention-induced weight changes.

In sharp contrast to the series of training studies, studies on stair use only used a before and after design, and only one of these was a controlled trial [16]. Shifting lift to stair use looks as an intuitively appealing strategy to increase habitual physical activity at the worksite. However, the design of such studies, as well as the definition of appropriate outcomes, makes it difficult to obtain high rankings with the chosen grading system for evidence of effectiveness. This may explain, at least in part, the inconclusive evidence found here for physical activity outcomes and the few data available for fitness as well as for obesity-related outcomes. In addition, it has been shown that the estimated gross energy expended during ascending and descending were equivalent to an intensity of 9.6 and 4.9 metabolic equivalents (METs) respectively [55]. This is not negligible but, considering the habitual duration of stair climbing in a typical working day, it may well not be enough to substantially affect body weight on the long term. One can however speculate that it could act as a starter for a more physically active lifestyle [56]. Along the same lines, when turning to commuting studies, it has been shown, that active transportation could increase adherence to activity recommendations [57] which could be a first step in the prevention of body weight gain. In this review, no effect on obesity outcomes was found for commuting studies in spite of moderate to limited evidence on physical activity/fitness outcomes. Altogether, a combination of interventions would seem as a promising approach. Multi-component approaches appear to have a higher potential impact on obesity-related outcomes [58]. Only one study of this type could be included in our review [42], and more data would be needed to assess evidence.

In previous literature, 2 meta-analyses focused on weightrelated outcomes $[9,10]$. These reviews included international studies and were not limited to Europe. The most recent and comprehensive review is the one by Verweij et al. [10]. In this meta-analysis, 14 studies on physical activity only were included. Only 5 among these studies were European studies also included in our review. The authors concluded that there was low quality of evidence that workplace physical activity interventions significantly reduce body weight (5 studies, mean difference between treatment and control $-1.08 \mathrm{~kg}$ (95\% CI -1.79 to -0.36$)$ ) and BMI (2 studies, mean difference $-0.50 \mathrm{~kg} / \mathrm{m}^{2}$ (95\% CI -0.46 to -0.22$)$ ); for body fat percentage (2 studies), evidence was rated as of very low quality with a non-significant effect (mean difference $-0.56 \%$ (95\% CI - 2.53 to 1.42)). Conn et al. [9] reported positive although modest and significantly heterogeneous effect sizes for anthropometric measures (BMI), requiring, according to the authors, cautious interpretation of findings. Findings from these previous reviews are difficult to compare to our results, given that we chose to analyse data according to type of intervention. In any case, it reinforces the need for more data on weight-related outcomes from interventions with a controlled design.

To our knowledge, this review is the first to apply the RE-AIM model in the context of physical activity interventions in the worksite setting. Success at translating behavioural programmes into public health practice means closer attention to the elements of a programme that can most easily be translated into practice [59]. The RE-AIM model provides a useful framework to determine programme strengths and weaknesses on this path from evidence to action.

Regarding reach and representativeness for individual participants, the participation rate was reported in the majority of studies. It was however not always clearly described and the denominator (eligible population) sometimes not indicated. Although almost all studies described their target audience, this description was not always detailed. Specifically, the term 'employee' was used but it is known that it may cover a wide variety of work tasks that may be more or less physically demanding [60]. At the setting level (adoption criteria), a majority of studies described the target setting, but the level of description varied widely and in general little information was provided on the company/institution studied. This is critical in attempts to transfer successful programmes according to socio-economic status, cultural background or type of resident location (urban/rural), to reach subgroups known at higher risk for weight gain and obesity [61].

Regarding implementation, at an individual level, most of the studies (52\%) involved 'trained staff' although the expertise or specific competences of this staff was seldom described. The role of the exercise supervisor, as well as his/her training, is known to be important to maintain high participation into programmes [62, 63]. Some kind of programme adaptation was reported in $21 \%$ of studies only, limiting possibilities to implement the programs in different contexts. Concerning maintenance and sustainability, these issues cannot be overlooked when dealing with obesity prevention. To assess the impact of behaviour modifications on body weight would require long-term (>12 months) intervention and follow-up. Only 1 study reported a long follow-up (1-6 years) [40]. High level of attrition and high variability in participation rates, in particular in the long term as observed here, challenge whether programmes fulfil their aims. In this field, a better understanding of reasons for drop-outs and the development of means to retain subjects into the programmes are needed. In some studies, incentives were offered as pull measures, either in form of gifts or even financial rewards, leading e.g. to a $31 \%$ increased participation to a walking programme in adults [64]. Importantly, sustainability of the programme was not reported except in one study [36]. This appears as crucial for decision-makers to consider the possibility to integrate physical activity in their policy development.

Some limitations of our review may be considered. We focused the search on physical activity and physical fitness outcomes, and we did not take into account interventions to 
reduce sedentary behaviour. Employees in many working sectors spend a substantial part of their time sitting [60]. A recent review emphasised the few data available and the current lack of evidence to show the effectiveness of workplace interventions for reducing sitting [65]. Another limitation may concern our focus on European studies only. It was our intention to identify types of interventions that could be generalised in European settings.

In conclusion, based on the evidence gathered in European adults, we would recommend providing exercise training programmes and facilitating active commuting (walking, cycling) in the worksite setting. These types of intervention were shown to increase components of physical fitness such as cardiorespiratory fitness, an important physiological risk marker. The potential importance of changing parts of the design of working places (e.g. stairs) to increase habitual physical activity level would need further assessment. There is currently too little evidence regarding the effect of worksite interventions on obesity-related outcomes to provide recommendations. However, body weight and body compo- sition outcomes should more systematically be included in workplace health promotion intervention studies. Finally, for translation into practice of worksite physical activity interventions, we would strongly advocate that the elements of generalisability and dissemination are better reported in future studies.

\section{Acknowledgment}

The project this paper is part of has been being carried out with financial support from the Commission of the European Communities, SP5ACT-2006-044128 'Health-Promotion through Obesity Prevention across Europe (HOPE): an Integrated Analysis to Support European Health Policy'. The study does not necessarily reflect the Commission's views and in no way anticipates the Commission's future policy in this area.

\section{Disclosure Statement}

The authors declared no conflict of interest.

\section{References}

1 Engbers LH, van Poppel MN, Chin APM, van Mechelen W: Worksite health promotion programs with environmental changes: a systematic review. Am J Prev Med 2005;29:61-70.

2 Katz DL, O'Connell M, Yeh MC, Nawaz H, Njike V, Anderson LM, Cory S, Dietz W: Public health strategies for preventing and controlling overweight and obesity in school and worksite settings: a report on recommendations of the Task Force on Community Preventive Services. MMWR Recomm Rep 2005;54:1-12.

$\checkmark 3$ Burton WN, Chen CY, Conti DJ, Pransky G, Edington DW: Caregiving for ill dependents and its association with employee health risks and productivity. J Occup Environ Med 2004;46:1048-1056.

4 Dishman RK, Oldenburg B, O'Neal H, Shephard RJ: Worksite physical activity interventions. Am J Prev Med 1998;15:344-361.

5 Dugdill L, Brettle A, Hulme C, McCluskey S, Long A: Workplace physical activity interventions: a systematic review. Int J Workplace Health Manag 2008;1:20-40.

6 Engbers LH: Monitoring and Evaluation of Worksite Health Promotion Programs - Current State of Knowledge and Implications for Practice. Geneva, World Health Organization, 2008.

7 Proper KI, Staal BJ, Hildebrandt VH, van der Beek AJ, van Mechelen W: Effectiveness of physical activity programs at worksites with respect to work-related outcomes. Scand J Work Environ Health 2002;28:75-84.

8 Proper KI, Hildebrandt VH, van der Beek AJ, Twisk JW, van Mechelen W: Effect of individual counseling on physical activity fitness and health: a randomized controlled trial in a workplace setting. Am J Prev Med 2003;24:218-226.

$\checkmark 9$ Conn VS, Hafdahl AR, Cooper PS, Brown LM, Lusk SL: Meta-analysis of workplace physical activity interventions. Am J Prev Med 2009;37: 330-339.
10 Verweij LM, Coffeng J, van Mechelen W, Proper KI: Meta-analyses of workplace physical activity and dietary behaviour interventions on weight outcomes. Obes Rev 2011;12:406-429.

11 Glasgow RE, Emmons KM: How can we increase translation of research into practice? Types of evidence needed. Annu Rev Public Health 2007;28: 413-433.

12 Glasgow RE, Vogt TM, Boles SM: Evaluating the public health impact of health promotion interventions: the RE-AIM framework. Am J Public Health 1999;89:1322-1327.

13 Green LW, Glasgow RE: Evaluating the relevance, generalization, and applicability of research: issues in external validation and translation methodology. Eval Health Prof 2006;29:126-153.

14 van Sluijs EM, McMinn AM, Griffin SJ: Effectiveness of interventions to promote physical activity in children and adolescents: systematic review of controlled trials. BMJ 2007;335:703.

15 Klesges LM, Dzewaltowski DA, Glasgow RE: Review of external validity reporting in childhood obesity prevention research. Am J Prev Med 2008;34:216-223.

16 Adams J, White MA: A systematic approach to the development and evaluation of an intervention promoting stair use. Health Educ J 2002;61:272286.

17 Eves FF, Webb OJ, Mutrie N: A workplace intervention to promote stair climbing: greater effects in the overweight. Obesity (Silver Spring ) 2006;14: 2210-2216.

18 Gamble RP, Boreham CA, Stevens AB: Effects of a 10-week exercise intervention programme on exercise and work capacities in Belfast's ambulance-men. Occup Med (Lond) 1993;43:85-89.

19 Gilson N, McKenna J, Cooke C, Brown W: Walking towards health in a university community: a feasibility study. Prev Med 2007;44:167-169.
20 Gilson ND, Puig-Ribera A, McKenna J, Brown WJ, Burton NW, Cooke CB: Do walking strategies to increase physical activity reduce reported sitting in workplaces: a randomized control trial. Int J Behav Nutr Phys Act 2009;6:43.

21 Hewitt JA, Whyte GP, Moreton M, van Someren KA, Levine TS: The effects of a graduated aerobic exercise programme on cardiovascular disease risk factors in the NHS workplace: a randomised controlled trial. J Occup Med Toxicol 2008;3:7.

22 Kennedy RA, Boreham CAG, Murphy MH, Young IS, Mutrie N: Evaluating the effects of a low volume stairclimbing programme on measures of health-related fitness in sedentary office workers. J Sport Sci Med 2007;6:454

23 Kerr J, Eves F, Carroll D: Six-month observational study of prompted stair climbing. Prev Med 2001;33:422-427.

24 Murphy MH, Murtagh EM, Boreham CA, Hare LG, Nevill AM: The effect of a worksite based walking programme on cardiovascular risk in previously sedentary civil servants [NCT00284479]. BMC Public Health 2006;6:136.

25 Mutrie N, Carney C, Blamey A, Crawford F, Aitchison T, Whitelaw A: 'Walk in to Work Out': a randomised controlled trial of a self help intervention to promote active commuting. J Epidemiol Community Health 2002;56:407-412.

26 Norris R, Carroll D, Cochrane R: The effects of aerobic and anaerobic training on fitness, blood pressure, and psychological stress and well-being. J Psychosom Res 1990;34:367-375.

27 Aittasalo M, Miilunpalo S, Suni J: The effectiveness of physical activity counseling in a work-site setting. A randomized, controlled trial. Patient Educ Couns 2004;55:193-202

28 Oja P, Mänttäri A, Heinonen A, Kukkonen-Harjula K, Laukkanen R, Pasanen M, Vuori I: Physiological effects of walking and cylcing to work. Scand J Med Sci Sports 1991;1:151-157. 
29 Perkiö-Mäkelä M: Influence of exercise-focused group activities on the physical activity, functional capacity, and work ability of female farmers - a three-year follow-up. Int J Occup Saf Ergon1999;5: 381-394.

30 Pohjonen T, Ranta R: Effects of worksite physical exercise intervention on physical fitness, perceived health status, and work ability among home care workers: five-year follow-up. Prev Med 2001;32: 465-475.

-31 Sjogren T, Nissinen KJ, Jarvenpaa SK, Ojanen MT, Vanharanta H, Malkia EA: Effects of a workplace physical exercise intervention on the intensity of headache and neck and shoulder symptoms and upper extremity muscular strength of office workers: a cluster randomized controlled cross-over trial. Pain 2005;116:119-128.

-32 Sjogren T, Nissinen KJ, Jarvenpaa SK, Ojanen MT, Vanharanta H, Malkia EA: Effects of a physical exercise intervention on subjective physical wellbeing, psychosocial functioning and general wellbeing among office workers: a cluster randomizedcontrolled cross-over design. Scand J Med Sci Sports 2006;16:381-390.

33 Talvi AI, Jarvisalo JO, Knuts LR: A health promotion programme for oil refinery employees: changes of health promotion needs observed at three years. Occup Med (Lond) 1999;49:93-101.

\$3 de Geus B, Joncheere J, Meeusen R: Commuter cycling: effect on physical performance in untrained men and women in Flanders: minimum dose to improve indexes of fitness. Scand J Med Sci Sports 2009;19:179-187.

35 Spittaels H, De Bourdeaudhuij I, Brug J, Vandelanotte C: Effectiveness of an online computertailored physical activity intervention in a real-life setting. Health Educ Res 2007;22:385-396.

36 Vanden Auweele Y, Boen F, Schapendonk W, Dornez K: Promoting stair use among female employees: the effects of a health sign followed by an e-mail. J Sport Exerc Psychol 2005;27:188-196.

37 Brox JI, Froystein O: Health-related quality of life and sickness absence in community nursing home employees: randomized controlled trial of physical exercise. Occup Med (Lond) 2005;55:558-563.

- 38 Gronningsaeter H, Hytten K, Skauli G, Christensen $\mathrm{C}$, Ursin $\mathrm{H}$ : Improved health and coping by physical exercise or cognitive behavioral stress management training in a work environment. Psychol Health 1992;7:147-163.

39 Osteras H, Hammer S: The effectiveness of a pragmatic worksite physical activity program on maximal oxygen consumption and the physical activity level in healthy people. J Bodyw Mov Ther 2006; 10:51-57.
40 Prior JO, van Melle G, Crisinel A, Burnand B, Cornuz J, Darioli R: Evaluation of a multicomponent worksite health promotion program for cardiovascular risk factors-correcting for the regression towards the mean effect. Prev Med 2005;40:259-267.

41 Titze S, Martin BW, Seiler R, Marti B: A worksite intervention module encouraging the use of stairs: results and evaluation issues. Soz Praventivmed 2001;46:13-19.

42 Titze S, Martin BW, Seiler R, Stronegger W, Marti B: Effects of a lifestyle physical activity intervention on stages of change and energy expenditure in sedentary employees. Psychol Sport Exerc 2001;2: 103-116.

43 Hendriksen IJ, Zuiderveld B, Kemper HC, Bezemer PD: Effect of commuter cycling on physical performance of male and female employees. Med Sci Sports Exerc 2000;32:504-510.

44 Kwak L, Kremers SP, van Baak MA, Brug J: A poster-based intervention to promote stair use in blue- and white-collar worksites. Prev Med 2007;45: 177-181.

45 Gerdle B, Brulin C, Elert J, Eliasson P, Granlund $\mathrm{B}$ : Effect of a general fitness program on musculoskeletal symptoms, clinical status, physiological capacity, and perceived work environment among home care service personnel. J Occup Rehabil 1995; 5:1-16.

46 Skargren E, Oberg B: Effects of an exercise program on musculoskeletal symptoms and physical capacity among nursing staff. Scand J Med Sci Sports 1996;6:122-130.

47 Brand R, Schlicht W, Grossman K, Duhnsen R: Effects of a physical exercise intervention on employees' perceptions quality of life: a randomized controlled trial. Soz Praventivmed 2006;51:14-23.

48 Puig-Ribera A, McKenna J, Gilson N, Brown WJ: Change in workday step counts, wellbeing and job performance in Catalan university employees: a randomised controlled trial. Promot Educ 2008;15: 11-16.

49 Pedersen MT, Blangsted AK, Andersen LL, Jorgensen MB, Hansen EA, Sjogaard G: The effect of worksite physical activity intervention on physical capacity, health, and productivity: a 1-year randomized controlled trial. J Occup Environ Med 2009;51:759-770.

50 Kerr J, Frank E, Douglas C: Can posters prompt stair use in a worksite environment? J Occup Health 2001;43:205-207.

51 Kerr J, Eves F, Carroll D: Encouraging stair use: stair-riser banners are better than posters. Am J Public Health 2001;91:1192-1193.
52 American College of Sports Medicine Position Stand: The recommended quantity and quality of exercise for developing and maintaining cardiorespiratory and muscular fitness, and flexibility in healthy adults. Med Sci Sports Exerc 1998;30:975-991.

53 Foster C, Cadwell K, Crenshaw B, Dehart-Beverley M, Hatcher S, Karlsdottir AE, Shafer NN, Theusch C, Porcari JP: Physical activity and exercise training prescriptions for patients. Cardiol Clin 2001;19:447-457.

54 Prentice AM, Jebb SA: Beyond body mass index. Obes Rev 2001;2:141-147.

55 Teh KC, Aziz AR: Heart rate, oxygen uptake, and energy cost of ascending and descending the stairs. Med Sci Sports Exerc 2002;34:695-699.

56 Mansi IA, Mansi N, Shaker H, Banks D: Stair design in the United States and obesity: the need for a change. South Med J 2009;102:610-614.

57 Berrigan D, Troiano RP, McNeel T, Disogra C, Ballard-Barbash R: Active transportation increases adherence to activity recommendations. Am J Prev Med 2006;31:210-216.

58 Lara A, Yancey AK, Tapia-Conye R, Flores Y, Kuri-Morales P, Mistry R, Subirats E, McCarthy WJ Pausa para tu Salud: reduction of weight and waistlines by integrating exercise breaks into workplace organizational routine. Prev Chronic Dis 2008;5:A12.

59 Estabrooks P, Gyurcsik NC: Evaluating the impact of behavioral interventions that target physical activity: issues of generalizability and public health. J Sport Exerc Psychol 2003;4:41-55.

60 Jans MP, Proper KI, Hildebrandt VH: Sedentary behavior in Dutch workers: differences between occupations and business sectors. Am J Prev Med 2007;33:450-454.

61 World Health Organization: Obesity: preventing and managing the global epidemic. WHO Technical Report Series 894, Geneva, 2000.

62 Robison JI, Rogers MA: Adherence to exercise programmes. Recommendations. Sports Med 1994; 17:39-52.

63 White JL, Ransdell LB, Vener J, Flohr JA: Factors related to physical activity adherence in women: review and suggestions for future research. Women Health 2005;41:123-148.

64 Brown DS, Finkelstein EA, Brown DR, Buchner DM, Johnson FR: Estimating older adults' preferences for walking programs via conjoint analysis. Am J Prev Med 2009;36:201-207.

65 Chau JY, der Ploeg HP, van Uffelen JG, Wong J, Riphagen I, Healy GN, Gilson ND, Dunstan DW, Bauman AE, Owen N, Brown WJ: Are workplace interventions to reduce sitting effective? A systematic review. Prev Med 2010;51:352-356. 